\title{
Attitudes towards the 'stranger': negotiating encounters with difference in the UK and Poland
}

Catherine Harris $^{a}$, Lucy Jackson ${ }^{b}$, Aneta Piekut $^{c} *$ and Gill Valentine ${ }^{a}$

${ }^{a}$ Department of Geography, University of Sheffield, Winter Street, Sheffield, S10 2TN, UK; ${ }^{b}$ Department of Geography, University of Liverpool, Roxby Building, Liverpool, L69 7ZT, UK; ${ }^{c}$ Sheffield Methods Institute (SMI), University of Sheffield, 219 Portobello, Sheffield, S1 $4 D P, U K$.

(Received 1 April 2014; accepted 26 October 2015)

\begin{abstract}
Due to recent intensification in international mobility in Europe, its citizens are exposed to a much wider range of lifestyles and competing attitudes towards difference. Individuals are therefore increasingly likely to encounter 'strangers' and are therefore required to negotiate discontinuities and contradictions between the values that are transmitted through different sites. In response, the paper explores the concept of the 'stranger' through original data collected in the UK and Poland. The paper highlights that the construction of who is a stranger depends on national historical contexts, core values and related visions of the society. The UK and Poland have very different histories and experiences with social diversity, impacting on the ways in which individuals negotiate strange encounters. In both countries the 'stranger' is often seen in a negative way and in relation to the minority groups that are perceived to be visibly different, distinct or 'unknown' in contemporary times. In Poland, this is now largely articulated through sexual prejudice (homophobia), whilst in the UK, attitudes towards the 'stranger' are largely conveyed through religious prejudice (Islamophobia). As such, the paper offers a means of understanding how encounters with difference 'produce' strangers in different contexts.
\end{abstract}

Key words: attitudes; stranger; Islamophobia; homophobia; UK; Poland.

* Corresponding author. Email: a.piekut@sheffield.ac.uk

Accepted manuscript for publication in Social \& Cultural Geography (26 October 2016), Doi: 10.1080/14649365.2016.1139165. 


\section{Introduction}

Europe has recently witnessed migration of an unprecedented scale. In this context, processes of globalization and accelerating social and geographical mobility mean that individuals are now exposed to a much wider range of lifestyles and competing attitudes towards difference, both positive and negative. Individuals are therefore increasingly likely to encounter 'strangers' and are required to negotiate discontinuities and contradictions between the values that are transmitted through different sites. This raises questions over how we define who is different from ourselves and how we negotiate relationships with 'others'. This is increasingly significant given the role of shared space in providing opportunities for encounters between strangers.

The relevance of this is reinforced through large amounts of theoretical discussions regarding the stranger in human geography and the broader social sciences. These include Simmel's (1908) seminal account of the stranger upon which a number of contemporary discussions are based, along with Lynn Lofland's (1973) account regarding a 'world of strangers'. Lofland's approach to the stranger has also influenced other scholars, including Amin's (2012; 2013) work, and has led to considerations of how we 'talk' to strangers (Allen, 2004) as well as considerations of the way in which strangers might indeed be familiar (Ahmed, 2000). Further, accounts of the stranger have highlighted contemporary concerns including multiculturalism (Amin, 2012; 2013) as well as international migration (Chambers, 2013). However, despite this abundance of theoretical discussion there is little research into the concept of the stranger as applied to specific groups and case studies, or indeed to the complexities inherent within the formation, and maintenance, of the category of 'stranger' (Jackson et al, this issue). In response, the paper explores the concept of the 'stranger' through original data collected in the UK and Poland to highlight the detailed and specific way in which accounts of, and encounters with, strangers occur. Through the examples of religious prejudice (Islamophobia) in the UK and sexual prejudice (homophobia) in Poland, the paper highlights that the construction of who is a stranger depends on national historical contexts and core values. The UK and Poland have very different histories of difference, migration experiences and social representation of 'otherness' in relation to the self. This impacts on the ways in which individuals conceptualise the stranger and negotiate 'strange encounters'.

In the research we avoid a direct comparison of Poland and the UK, instead using the two different contexts to underline the complexity and contextual nature of the 'stranger' figure in a way that allows us to move beyond a simplistic understanding of the concept. As a 
consequence, rather than employing a traditional comparison of narratives on encounters with difference in the UK and Poland, these two distinctive national contexts are treated as nodes and analytically linked with each other. We utilize the social topography approach here (Valentine, Piekut, Winiarska, Harris, \& Jackson, 2015b). The notion of social topography links some places analytically along lines that represent particular relations to the analysed social processes. By doing this we do not erase the uniqueness of particular place and national context, but rather we link them with a wider processes and with each other (Katz, 2001). In this paper we explore people's responses to difference and we analyse which minority groups are situated as strangers in both national contexts. The figure of stranger is not a pre-given and existing in absolute terms, but it is relational and constructed in everyday encounters. A person or a group is continuously constituted in everyday encounters in a continuum of positions between familiarity and strangeness (Simmel, 1908). Over the last two decades we see that in the British context the primary regime of producing strangers works along the axis of race, whilst in Poland it works along the axis of sexuality. Due to space constraints of this special issue paper, the full range of forms of othering cannot be presented, thus we concentrate on the two minority groups identified above, specifically Muslim people in the UK and sexual minorities in Poland. The visibility of both groups has recently increased in each context in terms of claimed rights and public discourse. Therefore investigating these groups enables us to focus upon the power and inequality between majority and minority groups in the contexts here discussed. As such, the paper contributes to debates in human geography on prejudice and encounters, whilst supporting the need for research which goes beyond theoretical and top-down discussions of the stranger.

The material used in this paper is taken from a large international research project "Living with difference in Europe: making communities out of strangers in an era of super mobility and super diversity", and mixed-method research was undertaken in Leeds, United Kingdom and Warsaw, Poland (Piekut, Rees, Valentine \& Kupiszewski, 2012; Valentine, Harris, \& Piekut, 2015a). While the first country represents a postcolonial power and the latter a postsocialist state, in both locations different racial and social hierarchies of power are reproduced (Mayblin, Piekut, \& Valentine, 2014). Moreover, both states are nowadays linked by a shared framework of European legislation and intra-EU mobility and intensive flows of attitudes, values and social practices (Valentine et al., 2015b). Leeds is the second largest metropolitan district in England and the regional capital. It has a long history of industrial diversification and prosperity, as well as long histories of immigration and significant levels of deprivation. The share of minority ethnic groups in Leeds is close to national average (app. 
17\%, 2011 Census). Warsaw was selected for the study since it is the most socially and ethnically diverse big city in Poland. The transformation of the political system in 1989 resulted in the opening of national borders, freedom of expression and speech (e.g. the possibility of open discussion on individual identities and difference in the public sphere) and equal treatment for all citizens. In this context Warsaw is considered to be the most cosmopolitan city in Poland where all forms of visible difference are present in public space, yet such encounters are situated in a conservative normative structure (Piekut, Vieten, \& Valentine, 2014).

In this paper we draw on an international survey which was carried out to explore patterns of prejudice $(n=3,023)$ and narrative interviews with respondents in Leeds and Warsaw $(\mathrm{n}=180$; three interviews with 30 participants in each city). Multi-method case studies and biographical interviews are used to explain when, where and how, attitudes towards strangers develop over time and how encounters with strangers are negotiated. The research participants represented a range of demographic characteristics, in terms of age, (dis)ability and socio-economic status, with some representatives of minority sexual, religious and ethnic groups. Qualitative interviews explored individual transmission values within family, experiences with social difference, everyday encounters with people who are different and reflections on national policy and dominant discourses regarding minority groups. Interviews were recorded, verbatim transcribed and coded in qualitative data software. Any names referred to in the quotations are pseudonyms.

\section{The stranger as concept and as construction}

The concept of the stranger, which has been widely discussed in the broader social sciences literature, is the key focus of this special. Discussions regarding the stranger highlight its changing nature as well as the importance of detailed empirical research in order to express the complexities of the term (Jackson et al, this issue). In this paper we take the debates raised in Jackson et al (this issue) forward by focusing on predominantly negative portrayals of the stranger through concepts of otherness (Simmel, 1908), of fear and threat to the social and moral order of a particular place. Moreover, we develop discussions regarding the socially constructed nature of the stranger, as well as the role of national and historical contexts in forming attitudes towards the stranger in different settings.

In 1973, Lynn Lofland's (1973) book, 'A world of strangers', focused on the idea of the stranger in the city. This work, which argued that the modern city was the product of a general shift in the way in which society deals with the presence of strangers in public space, 
was the basis of much contemporary thought regarding the stranger. Lofland suggested that what had changed was the dominant source of information upon which the categorical labelling took place. Influenced by this work, in 1988 Harman explored how the concept of the stranger changed through the twentieth century as urban life and demographics shifted. Harman argued that in the current era of residential mobility and social diversity, the stranger may be better seen as a cosmopolitan, expert navigator, moving between and making sense of the different communities in which she or he temporarily resides (Chambers, 2013). Further, Ash Amin's (2012) work develops the terminology and approach first introduced by Lofland (1973). Amin looks at the collapse of close social ties and the habits of modern living which characterise an increase in 'strangeness' brought about by migration, changes in community, and multicultural policies. Developing Amin's (2012) work, we therefore see a link between the stranger in the city and the stranger as a marker of identity category, most prominently of the migrant in urban encounters.

As externalised 'other' the notion of the stranger is constructed in/ by an assumption of fear which is based on categorical assumptions and a notion of contamination. This fear may come from the unpredictability of the stranger (Lupton, 1999) and develops Douglas' (1992, p. 58) assertion that 'people come already primed with culturally learned assumptions and weightings'. Such fear is projected onto groups or individuals, marked by their distinctness, their unknownness, their marker(s) of difference in different situated contexts (Harman, 1988). However, these categorisations only mark the projection of our internalised fears upon an externalised other, identified by their visible or social difference (Alexander, 2013). The threat induced by the stranger's difference may be characterised by a permanent sense of ambivalence (Koefoed, \& Simonsen, 2011) and by the very threat of bringing 'unknown' chaos into our 'known' world (Sandercock, 2000). Strangers, then, are seen as 'not like us' which constitutes the very threat they represent (Sandercock, 2000).

These associations of risk mark out more negative perceptions of the stranger as risk, but it is in social and historical context that such presumptions regarding an 'othered' identity are constructed. Here, strangers have been seen as a wave or flood (a notion often used to refer to migrants in the UK in the popular media, for example) which could engulf the 'us' (known) which, at their worst threaten the annihilation of an 'us' category (Sandercock, 2000). It is through the threat and fear of the unknown that we develop the literatures. Here, we focus on fear and threat not to the nation, but rather to social distinctions and categories of the other. We therefore focus on the stranger as unknown, which might be those characteristics "which are not common with the host groups or habitus" (Rundell, 2004, p. 86-87). However, the 
examples that we draw on also demonstrate the familiarity of the stranger, developing Sara Ahmed's (2000) conception of the stranger. Here, there is familiarity in unknown-ness, we recognise that someone is a stranger. As Ahmed argues, the figure of the stranger is 'painfully familiar' in its very strangeness. Through intricacies of visibility we discuss particular perceptions of categories of stranger in the different social, historical and cultural contexts, mapping these socio-spatial legacies onto how the stranger is seen and how such knownness is constituted by the categorisation of other.

In addition others have described the stranger as a position of interpretive failure or dispossession - the one who cannot, or who can no longer, understand the signs and symbols through which public communication takes place (Cooper, 2007, p. 203). Moreover, Danielle Allen's (2004) text discusses the concept of the stranger in regards to negotiating these differences in identity in order to overcome the structural inequalities within the world and to produce lessons in 'good citizenship'. Conversations around who, or what, is strange, or indeed stranger, have therefore developed over time to incorporate different components of inside/ outside and of self/ other. However, these discussions tend to focus on theoretical, rather than empirical, analyses of the stranger in everyday life. Further, much of this work focuses on a specific context, rather than on highlighting the importance of cross-comparative narratives in investigating the causality of stranger as definition. Finally, work on the stranger tends to be seen through the lens of multiculturalism and migration as identity category in the modern metropolis rather than 'other' 'othered' identities.

This paper advances discussions regarding the stranger as social construction, something which is a discursively produced position (Ahmed, 2000). These constructions are based upon assumed fears and the threat of the other, the outside, and the unknown, the binaries upon which categorisation exists. As actively constructed, '[s]trangeness is socially produced and material circumstances are very much involved...' (Alexander, 2013, p. 83). Such constructions, Alexander suggests, are based on assumptions that this other is "not quite human' in some way as we cannot understand their difference. The stranger as socially constructed is marked by its contextual nature (Koefoed, \& Simonsen, 2011). Here, the stranger is relational, and depends upon temporally, historical and social constructed-ness as well as contextual reference. If a stranger is feared or externalised in one context, it cannot be assumed that the same individual is also a stranger in an alternative context or situation. Our research, then, responds to these notions, highlighting the most prominent 'strangers' (or others) in two contrasting social, cultural, and political contexts, marked as distinct by their histories. Further, the two examples of socially constructed strangers within the empirical 
material respond to an earlier critique of many of the literatures which have thus far regarded the stranger as a primarily migrant other by changing the focus of the discussion to include identity categories not necessarily associated with migration.

We have argued that discussions regarding the stranger have tended to focus on social and cultural 'otherness', nominally migration status, as the foundation for construction of the stranger, we develop Heringa's (2013) research which suggests that a stranger's unknownness might also be represented by physical characteristics. The physical presence of 'the stranger' is therefore a consideration within our discussion. We suggest that situated encounters with strangers shape future perceptions and assumptions, of who, or what, are considered strange and subsequently the social construction of stranger identity in situated contexts. The research presented here therefore advances empirical and contextual discussions of the stranger, marking out the complexity of stranger as situated category.

\section{Situating research contexts: hierarchies of acceptance in Leeds and Warsaw}

We conducted representative surveys with adult populations in Leeds $(n=1524)$ and Warsaw $(n=1499)$ in which we asked people about perceptions of diversity and attitudes towards selected groups ${ }^{1}$. On a scale from 0 to 100 respondents were asked to say how warm their feelings were towards these groups. 0 equated to the coldest feelings and 100 to the warmest feelings. In Leeds the highest levels of prejudice were noted for travellers, gypsies and Roma people and refugees and asylum seekers. In Warsaw the highest levels of prejudice were towards gay and lesbian and transsexual people. Table 1 presents mean values of out-group attitudes towards selected minority groups of respondents in Leeds and Warsaw with standard deviations of these scores (the higher the score, the more dispersed the data is from the mean). There are statistically significant differences in the mean scores between the two cities in case of most attitudes.

\section{[Table 1 about here]}

In order to further explore patterns of prejudice we asked a follow-up question: "Thinking about the past 12 months, do you think your feelings towards any of these groups have become any colder? Can you say which has changed the most?". One in three respondents in both cities stated that their feelings towards one of 11 groups became cooler in the last year (see Figure 1$)^{2}$. In Leeds the highest percentage of people indicated travellers, gypsies, Roma people (31 per cent), refugees and asylum seekers (28 per cent) and Muslim people (27 per 
cent). In Warsaw the highest percentage of people indicated lesbian and gay people (22 per cent of positive answers), transsexuals (17 per cent), Muslim people (16 per cent) and travellers, gypsies, Roma people (15 per cent).

[Figure 1 about here]

The qualitative interview data for Poland strongly supports the findings of the survey. Intolerance of sexual minorities was a common theme throughout interviews with Polish respondents. However, in the UK interviews, the most significantly expressed prejudice amongst the interviewees was towards Muslim people, with less prejudice expressed towards travellers, gypsies and Roma people than the survey indicated. By focusing on these two forms of prejudice we do not claim that other prejudices are absent in the UK or Poland. For example, Islamophobia is also quite strong in the Polish context and recently on the increase. However, while homophobia is shaped in everyday, individual and embodied encounters with difference, prejudice towards Muslim people is fed by negative media reports on the events at the global or European scale. Thus, it is more abstract and in the literature it is called 'platonic Islamophobia' (Pędziwiatr, 2010).

Through investigating homophobia in Poland we seek to avoid a 'patronising discourse of help' coming from the Western Europe and our intention is not to frame Poland as a representative of Eastern European 'homophobic Other' (see Binnie, \& Klesse 2013, Kulpa, 2014). The historical context of Poland and its resultant core values go some way to explaining Poland's attitude towards strangers and particularly towards LGBT sexuality. Polish scholars underline that because of the specific Polish history- including, struggle for sovereignty during partition times (1772-1918), when the Church acted as a defender of Polishness, and the important role played by the Church in the communist opposition formation, i.e. the Church was a defender of human rights, the opposition was supported by the Pope John Paul II and the 'Solidarity' movement leaders were closely associated with the Church - Poles have developed a combined Polish-Catholic identity (Borowik, 2002). Religion was secularised and became interwoven with patriotism, and people developed a strong ritual bond with the church (ibidem). Also during socialism, religious sites were important spaces for opposition organisation and the Church supported the 'Solidarity' movement of 1980s. Paradoxically, this led to the exclusion of gender and sexuality freedoms from their agenda (Gruszczyńska, 2009). 
Family is also strongly valued by Polish people, e.g. in the European Values Survey 90 per cent of Poles mention family in the first place in the hierarchy of values. The majority of Poles recognise a traditional family model centred around a stable, long-term marriage, where having children is considered to be vital (Jasińska-Kania, 2009). In the socialist times, Polish state posed many constrains on expression of individual rights and liberties (e.g. elimination of private property, no liberty of association), and the private/family sphere - except the Church, which was exclusionary for minority sexualities - was the most important sphere of intimacy and locus of resistance against the state. Constraints imposed by the regime resulted in developing a specific approach towards the private sphere, which was perceived as something that has to be protected against the interference of political power (Heinen, 1997). This value given to the private sphere is connected with the family as a value, because family was the only space of freedom. In this context recent mobilisation of supporters of LGBT rights, especially since the 2005 presidential elections and the homophobic campaign of previous president Lech Kaczyński (Graff, 2010), and heated parliamentary debates on the possibility of rights to civil partnership in 2012-2013, have resulted in an increase in the public visibility and politicisation of gay and lesbian issues.

The UK has quite different core values to Poland due to its different historical context. It has seen a transformation from the British Empire into a multicultural nation state. It has secular values of equality with an emphasis on individualism and more liberal Anglican Church influences. Unlike Poland, its relaxed attitude towards sexual orientation developed in the post-Thatcher era and has been evident since the 1990s. However, there are some paradoxes which are emphasised by our survey results. The racialised boundaries of the nation from the colonial legacy remain with concerns over immigration, minority rights and Islam. This is often articulated through Islamophobia. As Modood (2008) explains, the incorporation of Muslims has become the most important challenge of multiculturalism in the UK. Whilst the Equality Act (2010) may have gone some way to achieving this incorporation, particularly in the workplace (Harris, \& Valentine, forthcoming) and increased the visibility of Muslims in the UK, prejudiced attitudes are still prevalent in other sites.

The September 11th terrorist attacks on the United States coupled with an increase in nonWestern migrants coming to Europe are often cited as the cause of a recent increase in hostility to Muslims in Europe. Islamophobia has in this period become a topic of increasing sociological and political importance. In a YouGov poll in $200284 \%$ of British people tended to be more suspicious about Muslims after 9/11 (Allen, 2010, p. 84). In $200582.6 \%$ of British Muslims surveyed reported an increase in religious discrimination post-September 
$11^{\text {th }}$ (Sheridan 2006). Events such as the 7/7 2005 bombings, the Salman Rushdie crisis, the political discourse around the British participation in the wars in Iraq and Afghanistan and a terrorist attack on a soldier in 2013 (both in London) have all emphasised Islamophobic attitudes in the UK. As Said (1978) and others have noted, ideas of 'otherness' in relation to Muslims in Europe draw on colonial discourses of civilization, racial hierarchy and exoticism which depict 'Muslim' and 'European' as mutually exclusive categories. This context explains why the qualitative data for the UK is slightly different to the survey. The overwhelming prejudice expressed in the interviews was religious prejudice, expressed as Islamophobia. Whilst research participants did discuss asylum seekers in a similar way to in the survey, they did not discuss them to the same extent as attitudes towards Muslims. This discrepancy might step from the increase in counter-terrorist measures in the UK, which have contributed to portraying the Muslim community as a 'suspect group' (Choudhury, \& Fenwick, 2011), and, in a consequence it has become more acceptable to express hostility towards this group (Allen, \& Nielsen, 2002).

The remainder of the paper explores attitudes towards the stranger through the examples of two forms of difference - religious difference in Leeds, often articulated through Islamophobia, and sexual difference in Warsaw, often expressed through homophobia. By contrasting these prejudices that have become recently more visible and politicised in each context, we aim to illustrate similarities in in how 'strangers' are socially constructed in everyday interactions, although they are situated in dissimilar national contexts.

\section{The Muslim as a stranger}

Terrorist attacks in the west this century and the war on terror, along with the rise of increasingly visible multicultural communities and the opposition to immigration featuring significantly in the public imagination and policy agendas, have all led to an increase in Islamophobic discourse in the UK. In line with this Islamophobic discourse, Muslims were often perceived as strangers in a negative way by our UK interviewees. This was predominantly articulated through the traditional notion of the stranger as the 'other' (Simmel, 1950; Lofland, 1973), as well as through a sense of fear and threat (Valentine, 1989; 1990; Lupton, 1999; Cooper, 2007), due to perceived extremist views and behaviour.

So there were plenty of other Muslim sort of people on there [the London Underground] and - but he was - never seen anyone like him before. He had a backpack on and he 
went into his - I was looking at him before he did and I was thinking I just don't like you being on the same train as me.

He went into his pocket and he pulled out what I thought were wires and I clearly panicked but they were like rosary beads - which again didn't make me feel great. I really panicked - my heart was going. There was no - I still don't think that was wrong to feel like that because I was - it wasn't just a little bit - I was legitimately really scared. I saw a policeman so I said, right. So I told the guy, I said, look I there's a guy that I can only describe as looking like an Afghan Taliban guy on the tube going that way (Male, 30-34).

Maybe I don't understand enough about it but... I just don't like anything I see about what Muslims do. Making bombs and living amongst us and, all right mate and next thing blowing us up (Male, 55-59).

Interviewees consistently framed discussions about Muslims as strangers, and particularly Muslim integration (or lack of) into 'mainstream' society, with reference to practices of veiling signifying them as visibly different. Indeed, as a number of scholars (Khiabany, \& Williamson, 2008; Abu-Lughod, 2002; 2006) have noted, alongside representations of Islam as an inherently violent culture, for our respondents, the Burka was particularly associated with threat:

Well, I'll see somebody dressed in an Islamic outfit and they might be wonderful people, but if they're dressed in Islamic tunics I automatically think, they're probably extreme, because they like to show, they like to put it on show... I see somebody in a hijab and I think [intake of breath] extremist stay away. Unfortunately, that's the way it is. It makes a big difference to me (Female, 50-54).

I think if all the minorities actually dressed in western style there wouldn't be half these problems that we've got to be honest. I think there's a - it's like tribal really isn't it. You can't help it if you're surrounded by people in different dress to you. You're supposed to feel sort of intimidated in a way (Male, 55-59).

I do not agree with [the burqa] wholeheartedly. I know it's their culture... but we're not living there. We're living in Britain. To somebody just to show their eyes, I find that quite threatening. You look at people's facial expressions, and just to see two eyes there, I find that very, very disconcerting and quite threatening (Male, 60-64). 
In addition to creating a sense of threat, the wearing of the veil, in various forms, was often depicted by interviewees as a purposeful separation and an act which prevented interactions from taking place (cf. Bartlett, 2006). Khiabany and Williamson (2008, p. 70) have suggested that there is a common image of 'Muslims as a homogenous block, backward and outside the historical process, tending towards extremism and refusing to integrate into British society'. We found such views echoed amongst our interview respondents:

These women who go around wearing hijabs and burkas, they're obviously separating themselves, because once you see that, down comes your shutters. You can't interact with people like that. Immediately that brings down a shutter when you see somebody dressed in that way, because they're making a distinction; I'm different from you. So therefore, how do you react to that? ... Being an atheist I'm not inclined to be sympathetic to them, but okay, if your religion is a barrier for you because it's separating you from the host community. A lot of these women, if they made themselves more presentable, took all this rubbish off their bodies and dressed like a European, nobody would know the difference, they would be accepted (Male, 55-59).

This lack of understanding as to why Muslims in the UK would choose to make themselves stand out as 'different', was a reoccurring theme and it is significant that the interviewee states that 'your religion is a barrier for you because it's separating you from the host community'. Conversely, both Dwyer (2008) and Hoodfar (1993) have found that the negative reaction of non-Muslims can actually present a significant barrier to integration.

Whilst it is often the Muslim woman who is usually cited as externally visible as the stranger, it is the behaviour of Muslim men which is perceived as 'strange' in our research. Respondents implicitly demonised Muslim men as the purveyors of extremist activity and gender oppression (cf. Hopkins, 2008; 2009). This supports Scott's (2003) discussion of male strangers. He argues that reinforcing these assumed rules of stranger danger can lead to moral panic around particular identities.

You see them [Muslim women] going shopping and stuff and you look at them and they always look really fed up. They're always getting shouted at by some bloke in their language. I don't know what they're saying (Female, 45-49). 
Well I mean they [Muslim men] treat their women terrible. Their women are scared stiff and I know that for a fact. I seen them shouting at them and they always cower (Male, 65-69).

Nevertheless, there were instances of respondents citing positive accounts of Muslim behaviour, illustrating that the stranger does not always have negative connotations but may be seen as positive, as enticing, exciting, erotic, albeit still marked by its difference (Cooper, 2007). Particularly, Muslims were praised for their strong family values and attitude towards finances.

\footnotetext{
When you look at the Muslims they've got a lot better values than what we've got to be honest with you, family values. Community spirit, you know, aside from looking at what we see day to day in the media with terrorism and one thing and another. When you get to the core of it and you speak to the genuine ones who just want the same as what we want for ourselves. You never see a poor Muslim, you never see a Muslim with debt or anything like that, because they all, they band together (Male, 30-34).
}

The negative comments made towards Muslims tend to be from older respondents (those over the age of 45), whereas this positive comment came from a younger respondent. This may be due to younger respondents having more opportunities for encounter with Muslims, such as growing up with Muslim friends at school and interacting with Muslim colleagues in the workplace. Contact in sites such as these can lead to the development of positive attitudes towards individuals from different social groups (Mayblin, Valentine, \& Andersson, 2015; Harris and Valentine, forthcoming).

Interestingly, neither of these positive and negative perceptions of the Muslim as a 'stranger' are founded on face-to-face verbal encounters or interactions with Muslims, rather they are socially constituted, discursively produced positions (cf. Ahmed, 2000) based on visual encounters. This demonstrates that encounters are at one level face-to-face meetings, but on another level are more than that. They are to a large degree also mediated: the present encounter presupposes other faces, other bodies, other spaces and other times as parts of its frame. In this way, participants' opinions seem to be justified in part by the fact that this behaviour has been 'seen' - actually witnessed. For our interviewees, Muslims are familiar strangers. Muslims are recognised from regular activities, but respondents did not base their perceptions of them as a stranger on interacting or communicating with them. This illustrates 
the significance of visual encounters and the national historical context of the UK along with the local-global production of fear (Pain, 2009), threat and terror. Indeed, terrorist attacks in the west this century and the war on/of terror have sparked new interest in the politics and patterns of fear. Other global (or at least deterritorialized) issues linked to terrorism, such as immigration, have also figured highly in the public imagination and on policy agendas (see Beck, 2002; Hujsmans, 2006). In such a way, this local-global production of fear, threat and terror is critical in shaping the attitudes towards the Muslim as a stranger in everyday life, rather than actual verbal face-to-face interactions or encounters with Muslims themselves.

\section{Sexual minorities as strangers}

In this section we aim to unpack prejudice towards sexual minorities in relation to core national norms and values in Poland and how they intersect with intolerance towards sexual minorities more broadly. We use this prejudice to unveil practices of social construction of 'strangeness' in the Polish context in relation to visibility of sexuality in the public sphere. Specifically, we argue that attitudes towards non-normative sexualities reflect the national imaginary of what should belong to the private and what to the public sphere (Heinen, 1997). In this imaginary, the visibility of non-normative sexualities is perceived as breaking the social contract of what should remain 'hidden', 'private' and kept outside the public gaze (Gruszczyńska, 2009). In this respect debates on the rights of gay and lesbian people in Poland and their inclusion into the 'majority' society could be read as negotiations of the 'familiar stranger' - the 'stranger within', the one who is recognised and visible, but with whom personal interactions are limited (Paulos, \& Goodman, 2004). Individual encounters with the 'visible-familiar stranger' subsequently led to renegotiations of the binary relation known/ unknown and demonstrates 'fluidity in action' of the stranger phenomena (Jackson et al, this issue).

After 1989, and especially in the last few years, sexuality has became visible and politicised, specifically in the presidential elections in 2005 (Graff, 2010). Hetero-normative public space and discourse have been challenged by LGBT activists and people supporting sexual minority rights; in other words, the social frames regarding who is defined as known / unknown have been shaken (Sandercock, 2000). Among our respondents a conservative view on the 'unwanted' visibility of sexual minorities was common. Even people who selfrepresented themselves as open and tolerant towards people of homosexual orientation expressed ambivalent feelings regarding the growing visibility of gay and lesbian people in the public sphere and public discourse. Gay and lesbian mobilisation is not perceived as a 
social movement expressed through democratic means, rather gay and lesbian people are rather accused of using the public place in an inappropriate way (Gruszczyńska, 2009). According to these narratives, sexual minorities should remain 'hidden' within the heteronormative majority, and should not 'expose' or 'flaunt' their difference:

These Equality Marches... This is nonsense to me, because if he (sic) has a different [sexual] orientation, he should keep it for himself [and] not show off, as it annoys people, you know. If somebody is normally raised, if one has normal views - and this [guy] shows up dressed as a woman or even worse (sic) - you know - such exposure, such behaviour - it pisses people off. (...) You cannot show off like this. [If] Something's wrong [with you], you're welcome to do these things your way, but don't insist on adoption of children or things like that - so that a child grows up having two daddies or mommies [sarcasm], right? Well, pardon me. (...) This is really a bit wrong, you know - in my opinion (Male, 75-79).

The 'strangers within', through their visibility, could also pose a threat towards others. The visibility of sexual minorities is perceived not only as inappropriate, but also as 'intruding' into the private spaces of the heterosexual majority (Graff, 2006). In this respect the 'familiar stranger' mobilises stored knowledge rooted in fears and threat that it could pose towards individual identities, safety and morality (Sandercock, 2000). As such, by revealing their sexual difference gay and lesbian people break the social contract twice: first, by including something that should be removed from the public, and second, by 'making' others see their difference and question their own selves. For example, a young female respondent objected to seeing and reading about gay and lesbian people online, because it penetrated her private space:

I've never said that I spit on these people and I've never said that - I don't know - I want to kill these people. But, you know, I just said that I didn't wish to watch it, right? This is my right, because Facebook is your personal space. For example, you've got restrictions there if you don't want to see some things. So, I consider it my private space. And I was - I hadn't said any harsh word or any unpleasant word - and I was attacked by her like this: "Hah hah, see - you're so embarrassing. It's you who's bad, who thinks wrong." And, since I think differently, I'm treated like her granny. And, grannies probably are treated like sort of dinosaurs in such situations, right? (Female, 25-29). 
It seems that both the public and the private are being threatened by visibility of sexual minorities. LGBT inclusion into 'mainstream' society is particularly opposed in relation to their equality claims on re-defining the collective definition of the family in terms of gender composition, although the political debate is polarised (Graff, 2006). For example, same-sex partnerships were usually described by respondents as acceptable (i.e. because of romantic or legal attachments of partners), but the idea of composing a family with children was strongly rejected. Such families were described as 'deviations' from the norm and not 'real' families. Additionally, equality claims made by non-heterosexual communities were opposed, because they did not assimilate into majority (Catholic) 'values'/'morality'/'rules' (cf. Mizielińska, 2001). These narratives further reveal the non-static nature of the 'familiar stranger' which is socially constructed and influenced by opinions of others (Cooper, 2007), but respondents' claims also support the belief that the stranger should be controlled (Jackson et al, this issue). Some respondents supported the 'normalisation' expectation and argued that if gay and lesbian people want the same rights as the majority, they should conform to the dominant rules of forming partnerships:

Let them stop hiding with all of that. Let them simply go out, let them live normally. And then the society would accept that, because in $90 \%$ of that society [nobody] would throw a stone at them (...) And they do not fit the Catholic principles, as it seems to me. (...) On the other hand such civil marriages should be allowed to them, but on the same principles, because they would like (...) an agreement which might be terminated at any time, right? (...) [The contract] is cancelled, but the other party does not have to be informed. That was what they wanted. (...) And when I want to divorce her [my wife], I must bear the consequences, right? So I have to get the divorce, the property must be divided and many other things. This is either this way or not at all, right? While they would like to have it arranged in such a strange manner to make their life easier, but they would not like to follow some rules (Male, 30-34).

Meanwhile, the claims of the rights to same-sex marriage/partnership made by LGBT activists reveal the 'heteronomativity' of their practices, because they actually do not challenge hegemonic relations, but embrace the collective understanding of the how national community should be reproduced (Kulpa, 2013) ratifying existing forms of family in its nonnegotiable form (Mizielińska, \& Stasińska, 2013). Such 'heteronormal' narratives about how 
sexuality should be 'managed' between the public and the private spheres was also normalised by one of our respondents, a gay man, who argued that his sexuality is his private issue and such values were learnt by him in the family home:

I didn't have to tell my uncle that I'm gay. He figured me out one day. (...) He said he just knew. And, he told me it wasn't a problem [for him] - woman being with another woman or a guy with another guy. [He said] You can do whatever you want at home... because, it is your own, private garden and it is accessed by the people whom you let in. Or - he tells me - by no one, if you don't want anyone to be there. But, he tells me, on the street, in some other [public] places? [He says] There are certain norms that need to be maintained. You have to follow [them], you need to maintain them. No matter if - he says - you're a lesbian [laughter], gay or straight. This is how it is - he says - and it should remain so. And, I do support the same view (Male, 30-34).

Conforming to the majority rules could be a result of experienced or anticipated discrimination. Heterosexual citizenship is reproduced in national imageries as known, proper and desired, but through employing 'normalisation' strategies sexual minorities remain invisible citizens (Binnie, 1997; Waitt, 2005). However, the interplay between their physical visibility and axiological invisibility turns homosexual people in Poland into the 'familiar stranger'; they remain in the liminal space between the familiar and the strange and they do not indicate any specific stranger(s), but a dynamic process in this spatial-temporal context (Lupton, 1999). The findings presented for Poland illustrate prevailing patterns of prejudice. Here, the core conservative values are questioned by minority groups and more often by a younger generation, we therefore see that the values and social norms are also being renegotiated. These social negotiations - on how sexual difference could be incorporated and challenge 'heteronormative' rules - lead to a paradoxical situation, however. Sexuality is socially expected to be hidden in a private space (within homes and within families), but at the same time gay and lesbian people are not given a right to form a 'normal'/'proper'/'regular' family and 'hide' their sexual difference in familial relations. Hence, the 'familiar stranger' is not given a right to exist either in the public or in the private space and is kept in the liminal space of strangeness. In sum, the construction of minority sexual groups as strangers is still framed in the context of the hegemony of traditional family values and conservative normative structure (Jasińska-Kania, 2009). 


\section{Conclusions}

This paper has explored the concept of the stranger through original empirical research. In doing so it demonstrates that understanding the stranger in everyday life is temporally situated in everyday histories and contexts. We have concentrated on two types of prejudice: religious prejudice in the UK, which is often articulated through Islamophobia, and sexual prejudice and homophobia in Poland. By doing this we do not claim that other forms of prejudice are absent in any of these societies. Both investigated minority groups are contemporarily seen in each national context as visibly different 'others'. As such their 'strangeness' is not fixed, but they become strangers through these encounters. Importantly, prejudice towards these groups is shaped through frequent everyday encounters and recently mobilised political discourses in each context. We have explored how the stranger is relationally reproduced in both national contexts using the social topography approach. We approached both places as nodes which can be analytically linked by looking at how the stranger is produced. The social construction of strangers could be seen a process of "selfunderstanding via the gaze of the Other" (Yuval-Davis 2010: 274) or creating boundaries which "signify the point at which 'we' end and 'they' begin" (Migdal 2004: 5). The UK and Poland have very different 'genealogies of difference' and are dissimilar in the type of otherness that is more visible and noticed. This impacts on the ways in which individuals conceptualise the stranger and negotiate strange encounters are temporally, historically and socially constructed. In both countries the 'stranger' touches upon the basic collective understanding of how the society should be reproduced, who is included as a 'good citizen' (Allen, 2004), and who does not fit the dominant narrative bringing 'unknownness' to the existing social order.

Although we have looked at two different forms of prejudice in two different national contexts, there are similarities in the way the stranger is relationally produced. In both presented cases, people produce boundaries to navigate their lives through complex social reality; they depend on visible 'checkpoints', like skin colour or assumed visual sexual difference, to predict how 'strangers' will act (Migdal, 2004, p. 11). In the UK attitudes towards the stranger are largely conveyed through Islamophobia, rooted in a sense of threat and a lack of integration, which are intrinsically linked to perceived extremist views and behaviour. The stranger is often discussed through a sense of fear and is cited in response to a visible external image - usually through the wearing of the veil. Interestingly, perceptions of the Muslim as a 'stranger' are not founded on actual encounters or interactions with Muslims. Rather, they have been shaped by events such as the $9 / 11$ and $7 / 7$ terrorist attacks. In this 
way, for our interviewees, Muslims are familiar strangers. In Poland, negative attitudes towards the stranger are often articulated through homophobia - while in UK Muslim stranger is seen as a threat and blamed for lack of integration, in Poland sexual minorities are expected to conform to the majority social norms. More importantly, the tensions around the hidden/visible stranger are related to the collective presumptions regarding how the nation should be reproduced; these values are connected with the dominant heteronormative understanding of gender relations in public and private spaces (Kulpa, 2013). Thus, we conclude that, in both national contexts, the figure of the 'familiar stranger' is relationally mobilised in relation to the growth in visibility of a minority group (visibility through seeing in public spaces and visibility as being present in public discourse), whose values are perceived to threaten the existing normative order. It is familiar since it is seen and discussed at everyday basis, but it belongs to the sphere of strange(r)ness, because it questions some core values and each society's self-representation.

Through these case studies, the paper advances discussions regarding the stranger as a social construction, something which is a discursively produced position (Ahmed, 2000). In both the UK and Poland these constructions are based upon assumed fears and the threat of the other, the outside, and the unknown. As such, the paper contributes to existing theories of the stranger by offering a means of empirically understanding how encounters with, and attitudes towards, strangers are negotiated in two different national contexts.

\section{Acknowledgements}

We are grateful to the European Research Council for funding the research on which this paper is based as part of the project "Living with Difference in Europe: making communities out of strangers in an era of super mobility and super diversity" - a European Research Council Advanced Investigator Award to Professor Gill Valentine (grant agreement no. 249658).

\section{Notes}

\footnotetext{
${ }^{1}$ The survey on attitudes and prejudice was conducted between February-April 2012. It was a Computer Assisted Person Interview (CAPI) at respondents homes. We applied a random location quota sampling design. This approach mixes a random selection of respondents' with more purposive sampling across different demographic profiles. Data were weighted in a post-fieldwork phase - for more details see (Valentine, Harris, \& Piekut 2015).

${ }^{2}$ Respondents could indicate only one group.
} 


\section{References}

Abu-Lughod, L. (2002). Do Muslim Women Really Need Saving? Anthropological Reflections on Cultural Relativism and Its Others. American Anthropologist, 104, 783-790.

Abu-Lughod, L. (2006). The Muslim woman: The power of images and the danger of pity. Eurozine. Retrieved from: http://www.eurozine.com/articles/2006-09-01-abulughod-en.html

Ahmed, S. (2000). Strange encounters: Embodied others in post-coloniality. London: Routledge.

Alexander, J. C. (2013). The dark side of modernity. Cambridge: Polity Press.

Allen, C. (2010) Islamophobia. Farnham, Surrey: Ashgate.

Allen, C., \& Nielsen, J. (2002). Summary Report on Islamophobia in the EU after 11. September 2001. Vienna: European Monitoring Centre on Racism and Xenophobia.

Allen, D. (2004). Talking to strangers. Chicago: University of Chicago Press.

Amin, A. (2012). Land of strangers. Cambridge: Polity Press.

Amin, A. (2013). Guest article: Land of strangers. Identities: global studies in culture and power, 20, $1-8$.

Bartlett, D. (2006, October 5th). Straw in Plea to Muslim Women: Take off your Veils. Lancashire Telegraph. Retrieved from: http://www.lancashiretelegraph.co.uk/news/954145.straw_in_plea_to_muslim_women_take_off_ your_veils/

Beck, U. (2002). The terrorist threat: world risk society revisited. Theory, Culture and Society, 19, $39-55$.

Binnie, J. (1997). Invisible Europeans: sexual citizenship in the new Europe. Environment and Planning A, 29, 237-248.

Binnie, J., \& Klesse, C. (2013). 'Like a Bomb in the Gasoline Station': East-West Migration and Transnational Activism around Lesbian, Gay, Bisexual, Transgender and Queer Politics in Poland. Journal of Ethnic and Migration Studies, 39, 1107-1124.

Borowik, I. (2002). The Roman Catholic Church in the process of democratic transformation: the case of Poland. Social Compass, 49, 239-252.

Choudhury, T., \& Fenwick, H. (2011). The impact of counter-terrorism measures on Muslim communities. Equality and Human Rights Commission Research, Report 72. Retrieved from: http://www.equalityhumanrights.com/sites/default/files/documents/research/counterterrorism_research_report_72.pdf

Chambers, I. (2013). Borders and beyond: reading in the margins of Ash Amin's land of strangers (2012). Identities: global studies in culture and power, 20, 9-17.

Cooper, D. (2007). Being in public: the threat and promise of stranger contact. Law and Social Inquiry, 32, 203-232.

Douglas, M. (1992). Risk and Blame: Essays in Cultural Theory. London: Routledge.

Dwyer, C. (2008). The Geographies of Veiling: Muslims Women in Britain. Geography, 93, 140-147.

Graff, A. (2006). We Are (Not All) Homophobes: A Report from Poland. Feminist Studies, 32, 434451.

Graff, A. (2010). Looking at pictures of gay men: political use of homophobia in contemporary Poland. Public Culture, 22, 583-603.

Gruszczyńska, A. (2009). Sowing the Seeds of Solidarity in Public Space: Case Study of the Poznan March of Equality. Sexualities, 12, 312-333.

Harman, L. (1988). The modern stranger. Berlin: Mouton de Gruyter. 
Harris, C., \& Valentine G. (forthcoming). Encountering difference in the workplace: superficial contact and underlying tensions. Available from authors.

Heinen, J. (1997). Public/private: Gender - social and political citizenship in Eastern Europe. Theory and Society, 26, 577-597.

Heringa, A., Bolt, G., \& Dijst, M. (2013). Strategies of avoidance and belonging: meanings of spatiotemporal whereabouts and responses to encounters with 'the other'. Paper presentation presented at the International and Interdisciplinary Conference on Emotional Geographies, 1-3 July 2013, University of Groningen, The Netherlands.

Hoodfar, H. (1993). The Veil in their Minds and On Our Heads: The Persistence of Colonial Images of Muslim Women. Resources for Feminist Research, 22, 5-18.

Hopkins, P. E. (2008). The Issue of Masculine Identities for British Muslims After 9/11: A Social Analysis. Lewiston, New York: Edwin Mellen Press.

Hopkins, P.E. (2009). Responding to the 'crisis of masculinity': the perspectives of young Muslim men from Glasgow and Edinburgh, Scotland. Gender, Place and Culture, 16, 299-312.

Hughes, G. (2007). Community cohesion, asylum seeking and the question of the 'stranger'. Cultural Studies, 21, 931-951.

Hujsmans, J. (2006). The politics of insecurity: fear, migration and asylum in the EU. London: Routledge.

Jasińska-Kania, A. (2009). Pole's Values. Social values recognized by Poles in a European context. Academia, 3, 8-11.

Katz, C. (2001). On the grounds of globalization: a topography for feminist political engagement. Signs: Journal of Women in Culture and Society, 26, 1213-1234.

Khiabany, G, \& Williamson, M. (2008). Veiled Bodies - Naked Racism: Culture, Politics and Race in the Sun. Race and Class, 50, 69-88.

Koefoed, L., \& Simonsen, K. (2011). 'The stranger', the city and the nation: on the possibilities of identification and belonging. European Urban and Regional Studies, 18, 1-15.

Kulpa, R. (2013). Nations and Sexualities - 'West' and 'East'. In R.Kulpa \& J. Mizielińska (eds.) DeCentring Western Sexualities. Central and Eastern European Perspectives (pp. 43-63). Farham: Ashgate.

Kulpa, R. (2014). Western Leveraged Pedagogy of Central and Eastern Europe: Discourses of Homophobia, Tolerance, and Nationhood, Gender, Place, and Culture. A Journal of Feminist Geography, 21, 431-448.

Lofland, L. H. (1973). A world of strangers: order and action in urban public space. Illinois: Waveland Press.

Lupton, D. (1999). Dangerous places and the unpredictable stranger: constructions of fear of crime. Australian and New Zealand Journal of Criminology, 32, 1-15.

Mayblin L., Piekut A., \& Valentine G. (2014). 'Other' posts in 'other' places: Poland through a Postcolonial lens? Sociology. Doi: 10.1177/0038038514556796.

Mayblin, L., Valentine, G., \& Andersson, J. (2015). In the contact zone: engineering meaningful encounters across difference through an interfaith project. The Geographical Journal. Doi: $10.1111 /$ geoj.12128

McLemore, S. D. (1970). Simmel's ‘Stranger’: A Critique of the Concept. The Pacific Sociological Review, 13, 86-94.

Migdal, J. S. (2004). Mental Maps and Virtual Checkpoints: Struggles to Construct and Maintain State and Social Boundaries'. In J.S. Migdal (ed.) Boundaries and Belonging. States and Societies in 
the Struggle to Shape Identities and Local Practices (pp. 3-26). Cambridge: Cambridge University Press.

Mizielińska, J. (2001). 'The rest is silience...' Polish nationalism and the question of lesbian existence. European Journal of Women's Studies, 8, 281-297.

Mizielińska, J. and Stasińska A. (2013). Od 'wroga rodziny' do jednej z jej form. Rodziny z wyboru we współczesnym polskim dyskursie prasowym. Inter Alia, 8, 105-128.

Modood, T. (2008). Is Multiculturalism Dead? Public Policy Research, 15, 84-88.

Pain, R. (2009). Globalized fear? Towards an emotional Geopolitics, Progress in Human Geography, $33,466-486$.

Paulos, A., \& Goodman, E. (2004). The Familiar Stranger: Anxiety, Comfort, and Play in Public Places. CHI 2004, 6, 23-30.

Pedziwiatr, K. (2010). Muslims in the Polish Media - the New Folk Devil? Arches Quarterly, 4, 8995.

Piekut A., Rees P., Valentine G., \& Kupiszewski. M. (2012). Multidimensional diversity in two European cities: thinking beyond ethnicity. Environment and Planning A, 44, 2988-3009.

Piekut, A., Vieten, U. M., \& Valentine, G. (2014). Seeking 'the New Normal'? Troubled spaces of encountering visible differences in Warsaw. Polish Sociological Review, 4, 541-558.

Rundell, J. (2004). Strangers, citizens and outsiders: otherness, multiculturalism and the cosmopolitan imaginary in mobile societies. Thesis Eleven, 78, 85-101.

Said, E. W. (1978). Orientalism. London: Routledge and Kegan Paul.

Sandercock, L. (2000). Negotiating fear and desire: the future of planning in multicultural societies, Urban Forum, 11, 201-210.

Scott, H. (2003). Stranger danger: Explaining women's fear of crime. Western Criminology Review, 4, 203-214.

Sheridan, L. P. (2006). 1slamophobia Pre and Post September $11^{\text {th }}$. Journal of Interpersonal Violence, $21,317-336$.

Simmel, G. (1908). Soziologie: Untersuchungen über die Formen der Vergesellschaftung. Leipzig: Duncker \& Humblot.

Simmel, G. (1950). The stranger. In K. Wolf (ed.), The sociology of George Simmel (pp. 402-408). Free Press, New York.

Valentine, G. (1989). The geography of women's fear. Area, 21, 385-390.

Valentine, G., Piekut A., \& Harris, C. (2015a). Intimate encounters: the negotiation of difference within the family and its implications for social relations in public space. The Geographical Journal, 181, 280-294.

Valentine, G., Piekut, A., Winiarska, A., Harris, C., \& Jackson, L. (2015b). Mapping the meaning of 'difference' in Europe: A social topography of prejudice. Ethnicities, 15, 568-585.

Waitt, G.R. (2005). Sexual Citizenship in Latvia: geographies of the Latvian closet. Social and Cultural Geography, 6, 161-181.

Yuval-Davis, N. (2010). Theorizing identity: beyond the 'us' and 'them' dichotomy. Patterns of Prejudice, 44, 261-80. 


\section{Tables and figures}

Table 1. Grand means of out-group attitudes in Leeds and Warsaw

\begin{tabular}{l|cc|cc}
\hline \multirow{2}{*}{ Attitudes towards ${ }^{a, b}$} & \multicolumn{2}{|c|}{ Leeds } & \multicolumn{2}{c}{ Warsaw } \\
\cline { 2 - 5 } & Mean & St. Dev. & Mean & St. Dev. \\
\hline Homeless people & 64.0 & 21.8 & 63.8 & 25.3 \\
Aged 65 and more *** & 79.6 & 19.3 & 83.5 & 19.2 \\
Gay \& lesbian *** & 65.7 & 24.2 & 50.4 & 30.4 \\
Muslim people *** & 62.2 & 24.3 & 53.5 & 27.4 \\
Disabled people *** & 79.1 & 19.4 & 85.3 & 19.6 \\
Black people * & 70.7 & 21.6 & 68.6 & 26.8 \\
Refugees \& asylum seekers *** & 52.8 & 25.1 & 62.1 & 25.8 \\
Jewish people *** & 69.7 & 21.0 & 60.4 & 28.3 \\
Travellers / gypsies / Roma people & 50.7 & 24.2 & 50.5 & 27.8 \\
Transsexual people *** & 58.1 & 24.2 & 43.5 & 31.4 \\
White people (in-group) $* * *$ & 76.5 & 20.2 & 85.9 & 19.6 \\
\hline Average out-group attitudes *** & $\mathbf{6 4 . 7}$ & $\mathbf{1 7 . 1}$ & $\mathbf{6 1 . 2}$ & $\mathbf{2 0 . 1}$ \\
\hline
\end{tabular}

Notes: ${ }^{a}$ We control for in-group favourism/bias and people belonging to particular groups were excluded in computing mean values (out-group attitudes). In case of White people in-group attitudes are presented.

${ }^{b}$ Significance of differences between cities: $* \mathrm{p}<0.05, * * \mathrm{p}<0.001, * * * \mathrm{p}<0.0001$.

Source: 'Living with Difference' survey 2012. 
Figure 1. Thinking about the past 12 months, do you think your feelings towards any of these groups have become any colder? (per cent of indications)

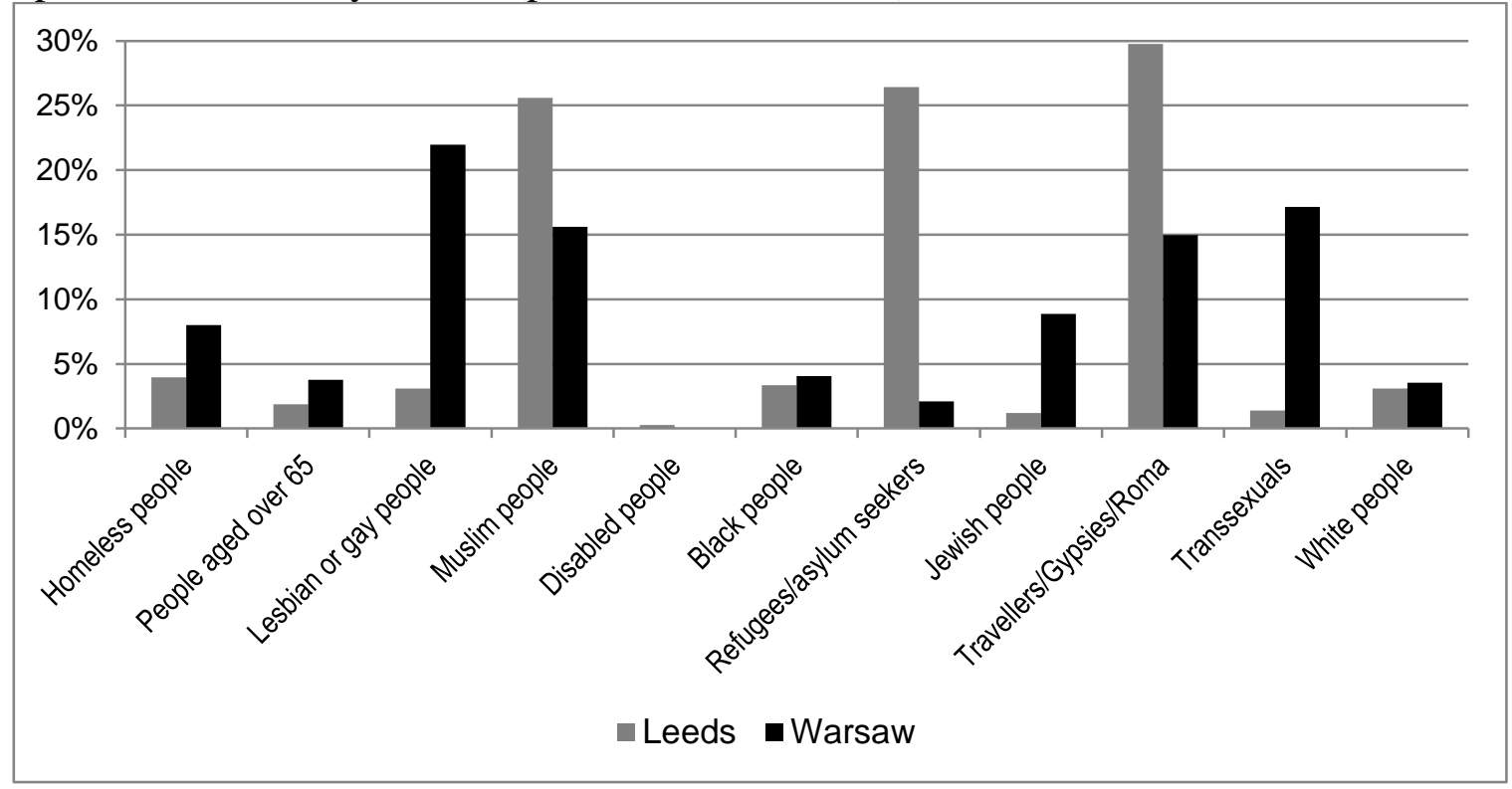

Notes: Percentage distribution for people whose feelings became cooler in last 12 months, Leeds $\mathrm{N}=434$, Warsaw $\mathrm{N}=333$.

Source: 'Living with Difference' survey 2012. 